Magnet i c properti es of the frust rat ed di anond chai $n$ compound $\mathrm{Cu} 3(\mathrm{CO}) 2(\mathrm{OH}) 2$

\begin{tabular}{|l|l|}
\hline 著者 & $\begin{array}{l}\text { K KUCH Hi kom t su, FUJII Yut aka, CH BA Nei ro, } \\
\text { M TSUDO Sei t ar o, I DEHARA Toshi taka }\end{array}$ \\
\hline $\begin{array}{l}\text { j our nal or } \\
\text { publ i cat i on t i tl e }\end{array}$ & Physi ca - Sect i on B \\
\hline vol une & $329-333$ \\
\hline nunber & 2 \\
\hline page r ange & $967-968$ \\
\hline year & 2003 05 \\
\hline URL & ht t p: //hdl . handl e. net /10098/1593 \\
\hline
\end{tabular}




\title{
Magnetic properties of the frustrated diamond chain compound $\mathrm{Cu}_{3}\left(\mathrm{CO}_{3}\right)_{2}(\mathrm{OH})_{2}$
}

\author{
Hikomitsu Kikuchi ${ }^{a}$, Yutaka Fujii ${ }^{a}$, Meiro Chiba ${ }^{a}$, Seitaro Mitsudo ${ }^{b}$, \\ Toshitaka Ideharab \\ a Department of Applied Physics, Fukui University, Fukui 910-8507, Japan \\ ${ }^{b}$ Research Center for Development of Far-Infrared Region. Fukui University, Fukui 910-8507, Japan
}

\begin{abstract}
$\mathrm{Cu}_{3}\left(\mathrm{CO}_{3}\right)_{2}(\mathrm{OH})_{2}$ (azurite), in which $\mathrm{Cu}^{2+}\left(S=\frac{1}{2}\right)$ monomers and dimers are arranged alternately along the $b$-axis to make an infinite chain, is regarded as an actual material for the frustrated diamond chain model. we have measured magnetic susceptibility, high field magnetization and ${ }^{1} \mathrm{H}$ NMR of a natural mineral single crystal of azurite to investigate the magnetic properties. The experimental results were compared with the theoretical expectation to suggest the ground state of $\mathrm{Cu}_{3}\left(\mathrm{CO}_{3}\right)_{2}(\mathrm{OH})_{2}$ is in a gapless phase.
\end{abstract}

Keywords: Quantum spin system; One-dimensional magnet; Spin frustration

\section{Introduction}

The influence of the spin frustration on a ground state of a quantum spin system is of great interest and has been studied actively. One of the most simple frustrated quantum system is the diamond chain in which diamond-shaped units compose one-dimensional lattice (Fig. 1). Takano and his coworker [1] theoretically studied the ground state of the diamond chain and found that the system underwent phase transitions as the ratio between the exchange parameters was changed. Experimental works concerning the magnetic properties on the diamond chain however have not progressed because of a lack of the good model substance. We have found that a compound $\mathrm{Ca}_{3}\left(\mathrm{CO}_{3}\right)_{2}(\mathrm{OH})_{2}$ (azurite), in which $\mathrm{Cu}^{2+}\left(S=\frac{1}{2}\right)$ monomers and dimers are arranged along the $\dot{b}$-axis to make an infinite chain [2], to be regarded as the actual model material for the diamond chain. In order to elucidate the magnetic properties of this material, we have measured magnetic susceptibility
$\gamma(T)$, high field magnetization and ${ }^{1} \mathrm{H}$ NMR on a natural mineral single crystal of $\mathrm{Cu}_{3}\left(\mathrm{CO}_{3}\right)_{2}(\mathrm{OH})_{2}$.

\section{Experimental details}

The single crystal samples of azurite were purchased at a stone shop. Quality of the sample was checked by a powder $\mathrm{X}$-ray diffraction pattern. The magnetic susceptibility was measured using quantum design SQUTD magnetometer in the temperature range $5-300 \mathrm{~K}$. The magnetization curve up to $35 \mathrm{~T}$ was measured using pulsed magnet. The ${ }^{1} \mathrm{H}$ NMR spectra and the spinlattice relaxation time were measured by a pulsed spin echo method in the temperature range from $1.5 \mathrm{~K}$ to room temperature.

\section{Results and discussion}

Fig. 2 shows the temperature dependence of $\chi(T)$. The magnetic field of 100 Oe was applied parallel or perpendicular to the $b$-axis of the single crystal.

Broad maxima have appeared in $\chi(T)$ curves at around $20 \mathrm{~K}$, indicating the one-dimensional nature of 


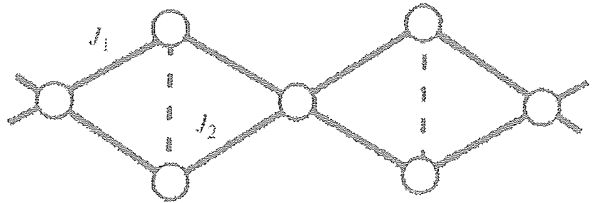

Fig. 1. Schematic diagram of a diamond chain model. Open circles stand for the $S=\frac{1}{2}$ spins. $J_{1}$ and $J_{2}$ mean the exchange couplings between adjacent spins.

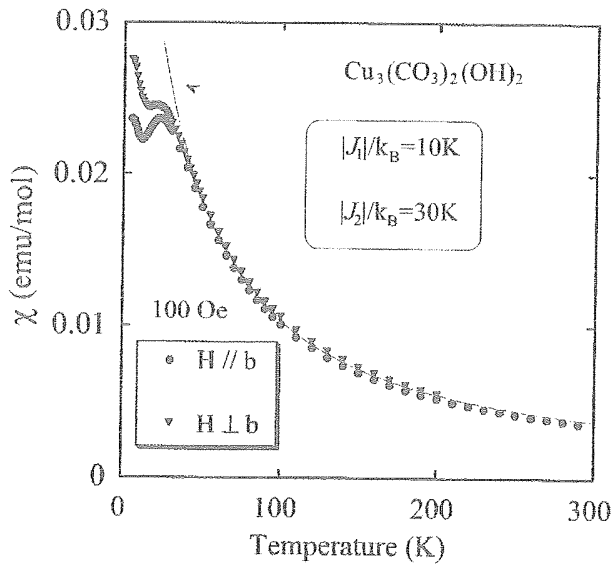

Fig. 2. The temperature dependence of the magnetic susceptibility of a single crystal of $\mathrm{Cu}_{3}\left(\mathrm{CO}_{3}\right)_{2}(\mathrm{OH})_{2}$ measured in field of 100 Oe applied parallel and perpendicular to the $b$-axis. The solid curve is a fitting result using the high temperature expansion series with $\left|J_{1}\right| / k_{\mathrm{B}}=10 \mathrm{~K}$ and $\left|J_{2}\right| / k_{\mathrm{B}}=30 \mathrm{~K}$.

$\mathrm{Cu}_{3}\left(\mathrm{CO}_{3}\right)_{2}(\mathrm{OH})_{2}$. Uptums seen in low temperature part of the susceptibility may be attributed to the small amount of magnetic impurities. Fig. 3 shows the magnetization curve measured at $4.2 \mathrm{~K}$ in the applied field parallel to the $b$-axis. In lower feld region, the magnetization was nearly proportional to the applied magnetic field, which inferred that a spin gap is not present in this system. Above about $30 \mathrm{~T}$, the magnetization increased abruptly and saturated at about $35 \mathrm{~T}$. The value of the saturation magnetization was about $1.0 \mu_{\mathrm{B}}$ which agreed well with an expected value for $S=$ $\frac{1}{2}$. A shape of this magnetization curve is different from that usually observed in a simple 1D antiferromagnet without the spin frustration.

The magnetic coupling constants were tried to estimate using the high-temperature expansion series for $\chi(T)$ [3]. The calculated susceptibility with $\left|J_{1}\right| / k_{\mathrm{B}}=$

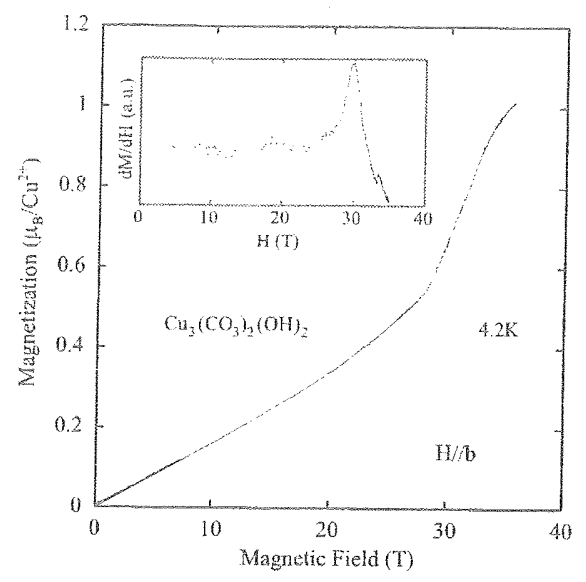

Fig. 3. The high ficld magnetization curve of $\mathrm{Cu}_{3}\left(\mathrm{CO}_{3}\right)_{2}(\mathrm{OH})$ measured at $4.2 \mathrm{~K}$. The magnetic ficld was applied along $b$ waxis. Inset is a field derivative of the magnetization (abbitrary unit).

$10 \mathrm{~K}$ and $\left|J_{2}\right| / k_{\mathrm{B}}=30 \mathrm{~K}$, shown in a solid curve in Fig. 2, agreed well with the experimental result. According to the theory [1], if $\left|J_{2} / J_{1}\right|>2$ the ground state of the diamond chain systcm enters the gapless tetramermonomer phase. $\left|J_{2} / J_{1}\right|$ was estimated to be 3 through the fitting procedure, so that $\mathrm{Cu}_{3}\left(\mathrm{CO}_{3}\right)_{2}(\mathrm{OH})_{2}$ is expected to be gapless, being consistent with the experimental result.

The magnetic long range order was reported to occur at about $2.0 \mathrm{~K}[4]$. We have observed the sharp peak of the spin-lattice relaxation rate of ${ }^{1} \mathrm{H}$ at $2.0 \mathrm{~K}$, agreed well with the reported transition temperature.

\section{Acknowledgemenous}

This work is supported by Grant-in-Aid for Scientific Research on Priority Areas (B) (No. 13130204) from the Ministry of Educations, Culure, Sports, Science and Technology, Japan.

\section{呫eferences}

[1] K. Takano, K. Kubo, H. Sakamoto, I. Phys.: Condens. Matter 8 (1996) 6405

[2] F. Zigan, H.D. Schuster, Z. Kristallogr. 135 (1972) 416.

[3] A. Honecker, A. Läuchli, Phys. Rev. B 63 (2001) 174407.

[4] M. Garber, R. Wager, Physica 26 (1960) 777. 